has been accomplished by an association supported with the assistance of the Board of Control, the L.C.C., and many boards of guardians. Moreover, the Association's example has been followed in Europe, as well as in America and Japan. This, therefore, is a striking example of the difficulty of eliciting practical sympathy for its support

I am, Sir, yours faithfully

H. RAYNER, M.D.,

March 4th, 1922

Chairman of the Mental After Care Association.

\section{A POST-GRADUATE DIPLOMA.}

To the Editor of THE LANCET.

SIr,-Is it not probable that lack of incentive in form of special academic reward is one reason why post-graduate work fails to make the appeal it should to the home practitioner? It might be satisfactory to have something to show on paper or parchment as the result of labours in clinic and classroom. Postgraduate interest in London badly needs a stimulus, and I suggest the institution of reasonably accessible academic distinctions for the " old boys" as a step in the right direction.

I am, Sir, yours faithfully,

London, W., March 6th, 1922. EDWIN L. ASH, M.D.

\section{GERMAN APPARATUS.}

To the Editor of THE LANCET.

SIR,-The letter by "A Manufacturer of British Apparatus" in your issue of Feb. 25th, dealing with $\mathrm{X}$ ray material, raises a point which requires elucidation. The writer complains of German competition and its deadly effects upon British scientific industry. Personally, this problem is constantly with me in an acute form. On the one hand, one earnestly desires to purchase British manufactures, and whenever possible this is done, yet it is found that certain apparatus is made cheaper, and in some cases better by alien firms, and in the present state of hospital finance we simply must purchase the more economical article. Only this week, I ordered a special type of high-power microscope lamp. The price by Reichert, the Viennese firm, was something like six times less than the British quotation. The biochemical laboratory of a hospital at Cambridge, so I am told, required a new chemical balance. The alien firm quoted $£ 30$ for a beautiful instrument fitted with a microscope for viewing the vernier and weights turned out in quartz. The British firm quoted $£ 60$ for an article not so good.

This is what we have to contend with. The hospitals are short of funds partly because the new rich will not subscribe to anything like the extent that the former patrons did. The new rich are mainly of the manufacturing class. It seems, therefore, that the remedy lies in the hands of the manufacturing class-namely, a smaller margin of profit, increased efficiency, and more liberal support for the hospitals which would enable the institutions to purchase British apparatus at reasonable prices.

Incidentally, the worker also must do his share, and he is bestirring himself, but to my mind he is much the less potent cause of a deplorable state of affairs.-I am, Sir, yours faithfully,

A. Geoferey Shera, M.D. Camb. Feb. 28th, 1922. Pathologist, Princess Alice Hospital, Eastbourne.

\section{A DIAGNOSTIC GESTURE IN NEURASTHENIA ? \\ To the Editor of THE LANCET.}

SIR,-I have several times noticed, in ex-Service men under treatment for "neurasthenia," a connexion between a certain gesture of the hands and a definite type of patient. From the position of rest when seated, with elbows, wrists, and fingers slightly flexed, and the ulnar side of the forearms resting on the upper part of the thighs, the movement is a sort of jerk of one or both hands ; in detail there is extensior of the wrist and abduction of the forearm, the finger- tips travelling about a foot. On completion the movement is reversed, but is much slower. There may be an interval, varying from a few seconds to some minutes, before the next movement, or the movements may be continuous; in this case there is no complete return to the resting position, but a to and fro movement, like playing a concertina. The gesture accompanies the patient's description of his symptoms, feelings, or experiences, and varies in frequency and extent directly with the amount of emotion present.

The cases with this gesture have all been men with the obsessions, phobias, folie du doute, and, frequently, hallucinations characteristic of compulsion hysteria; most of them were young single men who have not been exposed to any great danger, but whose illness has been attributed to heat-stroke, malaria, or influenza, or who have broken down during training at home. They are all very talkative and many have a most retentive memory for all details of their interviews, usually numerous, with various doctors. The patients themselves appear quite unaware of the habit, which I have come to regard as almost pathognomonic. Of course, it does not occur in all compulsion cases. I I $\quad$ Sir, yours faithiully,

E. C. Plumamer

Neurological Clinic, Plymouth, March 6th, 1922.

\section{CO-EDUCATION IN MEDICINE.}

\section{To the Editor of THE LANCET.}

SIR, - The causes of the opposition encountered by the pioneers of medical education for: women seem obscure to us now, and the reasons that were advanced have not stood the test of time ; they were probably rationalisations, or reasons adduced to support a judgment already formed. The decision of the London Hospital authorities to cease admitting female students, because of the awkwardness of dealing with unpleasant subjects before a mixed class, depends upon a recognition of emotional inhibitions, though the experience of medical schools in the provinces, as well as in Scotland, Canada, and Australia, where mixed classes have been the rule for a long time, would suggest that these inhibitions are a local survival. The tendency of to-day is to remove certain restraints upon discussion, and our profession is properly looked to for a lead in regard to subjects, such as venereal disease, which were quite recently held to be unmentionable in public; the medical man or woman must be prepared to view these subjects clearly and without timidity. As a matter of fact, medical training has always had the effect of removing any feelings of embarrassment that would hinder the proper investigation, say, of physical disorders of the sex organs, and it is becoming necessary that a similar attitude should be cultivated towards the mental aspect of sex functions. The cultivation of such an impersonal and scientific attitude to patients of the opposite sex can hardly succeed if it fails between medical students of opposite sex or between a teacher and a mixed class.

The coming together of students of both sexes seems to have had no striking consequences. A fair number of marriages take place, as would happen in any similar grouping of young adults, and the female partner probably retains her connexion with medicine, which would be unlikely to happen in the case of her marrying an outsider. No disadvantageous results have been noted, and the association of men and women during the study period can only add to that knowledge of mankind and womankind, which is as necessary as the more definite objects of the curri culum. In the case of those medical schools that maintain the exclusion of female students the factor leading to the exclusion are probably multiple and indefinite. If the interests of the school are best served by following that principle, it is difficult to question the right to do so. The athletic side of a school, which may be affected by an influx of women, has great influence upon the type of men who enter it, and there is, perhaps, enough diffidence among young 